\title{
Kesesuaian lahan untuk pengembangan tanaman kayu putih dan implikasinya terhadap teknik silvikultur
}

\section{Land Suitability for Cajuput Development and its Inference on Silviculture Strategy}

\author{
Ronggo Sadono ${ }^{\mathrm{a}}$, Djoko Soeprijadi ${ }^{\mathrm{a}}$, Pandu Y.A.P. Wirabuana ${ }^{\mathrm{b}}$ \\ aDepartemen Manajemen Hutan, Fakultas Kehutanan, Universitas Gadjah Mada, Jln. Agro No. 1 Bulaksumur, Yogyakarta 55281 \\ ${ }^{b}$ Departemen Penelitian dan Pengembangan, Trofsit, Jln. Kaliurang km 16, Yogyakarta 55281
}

\section{Article Info:}

Received: 06 - 09 - 2019

Accepted: $21-11-2019$

\section{Keywords:}

Cajuput, land suitability, strategy, silviculture

Corresponding Author: Pandu Y.A.P. Wirabuana Departemen Penelitian dan Pengembangan, Trofsit; Telp. $+6281-226887738$

E-mail:

pyapwirabuana92@gmail.com

\begin{abstract}
Cajuput is a plant that plays a key role for forest industry development. Its leaves contain essential oil and become one of the non-timber forest products. The productivity of cajuput leaves is affected by certain factors, one of them are the level of land suitability. This study identified the land suitability for cajuput establishment and its inference on silviculture strategy. Study location was situated in Forest Resort Gubugrubuh, Gunungkidul District. Data collection was conducted in 3 site that was converted as the priority site of cajuput plantation namely site 75, site 78, and site 80. We used six variables of land attributes covering altitude, slope, rainfall, temperature, soil acidity, and soil organic carbon. Land suitability was determined by qualitative approach using storie and root square method. Results demonstrated the level of land. land suitability was classified into NI (currently not suitable) referring to the storie method while it was categorized into $S 3$ (marginally suitable) according to the root square method. This study also recorded the difference land attributes which became the limiting factors of cajuput growth in every site. The best silviculture strategies for supporting cajuput development in each site were terrace construction, fertilization, and spacing management.
\end{abstract}

How to cite (CSE Style $8^{\text {th }}$ Edition):

Sadono R, Soeprijadi D, Wirabuana PYAP. 2019. Kesesuaian lahan untuk pengembangan tanaman kayu putih dan implikasinya terhadap teknik silvikultur. JPSL 10(1): 43-51. http://dx.doi.org/10.29244/jpsl.10.1.43-51.

\section{PENDAHULUAN}

Kayu putih merupakan tanaman yang memiliki peranan penting untuk pembangunan industri kehutanan. Tanaman ini memberikan berbagai manfaat secara ekologi, ekonomi, dan sosial (Junaidi et al., 2015). Kayu putih termasuk kategori fast growing species (FGS) yang dapat digunakan untuk mempercepat proses suksesi pada lahan kritis seperti kawasan karst (Page et al., 2009) serta restorasi ekosistem gambut (Tata \& Pradjadinata 2015). Spesies ini juga dapat dikembangkan sebagai tanaman remediasi pada tanah terkontaminasi (Mohd et al. 2013). Kayu putih sangat adaptif untuk dibudidayakan melalui sistem agroforestri sehingga meningkatkan peluang untuk mendukung program ketahanan pangan (Suryanto et al., 2017). Daun kayu putih mengandung minyak atsiri yang bermanfaat untuk industri obat-obatan dan kosmetik. Hingga saat ini, minyak kayu putih menjadi produk hasil hutan non kayu (HHNK) yang bernilai ekonomi tinggi dengan potensi pasar yang cukup prospektif (Budiadi dan Ishii, 2010). Sebagai komoditi kehutanan, kayu putih telah banyak dikembangkan baik di hutan negara maupun hutan rakyat. Pengelolaan kayu putih secara intensif telah banyak diupayakan, salah satunya di Pulau Jawa (Budiadi et al., 2006). Potensi kayu putih sebagai produk HHNK berkontribusi positif terhadap pendapatan perusahaan ketika suplai kayu dari hutan negara mulai 
menurun. Produktivitas kayu putih bervariasi tergantung karakteristik lahan yang menjadi habitatnya (Budiadi et al., 2005; Helfiansah et al., 2013).

Lahan merupakan sumberdaya yang mempunyai posisi strategis dalam mendukung industri pertanian dan kehutanan (Memarbashi et al., 2017). Sifat-sifat lahan meliputi iklim, topografi, dan tanah memiliki pengaruh signifikan terhadap pertumbuhan tanaman (Malekian dan Jafarzadeh, 2011). Karakteristik lahan dapat berfungsi sebagai katalisator maupun inhibitor bagi pertumbuhan tanaman (Sharififar, 2012). Pemanfaatan lahan secara optimal dapat menghasilkan produktivitas tanaman yang tinggi. Kondisi tersebut sangat ditentukan oleh kelas kesesuaian lahan dalam mendukung prasyarat tumbuh tanaman (Girma et al., 2015). Dalam konteks tersebut, kesesuaian lahan merupakan landasan informasi untuk menentukan strategi pengelolaan hutan tanaman yang meliputi (1) pemilihan alternatif jenis tanaman yang berinteraksi positif dengan atribut lahan (Nethononda et al., 2014); (2) penyusunan strategi silvikultur untuk meningkatkan kualitas tanah melalui skenario manipulasi lingkungan terhadap faktor pembatas lahan (Zhang et al., 2015); (3) penentuan teknik konservasi tanah dan air untuk mempertahankan kesuburan tanah serta mengurangi erosi (Dengiz et al., 2010); serta (4) pengaturan pola tanam untuk mengendalikan kompetisi antar tanaman sehingga dapat menghasilkan pertumbuhan yang optimal (Bhagat, 2012).

Meskipun memiliki daya adaptasi yang tinggi terhadap berbagai variasi kondisi lingkungan, Sudaryono (2010) dan Dibia (2015) mendokumentasikan bahwa kayu putih secara prinsip akan tumbuh dengan baik pada lahan yang terletak di dataran rendah dengan konfigurasi relatif datar. Tanaman ini dapat berkembang dengan baik pada kondisi tergenang maupun kering. Akan tetapi, rendemen minyak kayu putih akan lebih banyak dihasilkan oleh tanaman yang tumbuh di daerah kering dengan curah hujan tahunan $<1.500 \mathrm{~mm} / \mathrm{tahun}$. Kemasaman tanah yang netral dengan kandungan bahan organik yang rendah sangat sesuai untuk pertumbuhan tanaman kayu putih.

Penelitian ini bertujuan untuk mengidentifikasi tingkat kesesuaian lahan pada lokasi pengembangan hutan tanaman kayu putih yang terletak di Resort Pengelolaan Hutan (RPH) Gubugrubuh. Informasi ini selanjutnya akan digunakan untuk untuk merumuskan teknik silvikultur yang dapat digunakan untuk mendukung upaya pengembangan kayu putih pada kawasan tersebut. Evaluasi kesesuaian lahan dilakukan dengan mekanisme perbandingan antara prasyarat tumbuh kayu putih dengan karakteristik lahan yang terdapat pada lokasi studi. Data prasyarat tumbuh kayu putih dikumpulkan dari studi literatur yang mengkaji tentang tanaman kayu putih. Dilain pihak, survey lapangan dilaksanakan untuk mengukur karateristik lahan pada setiap petak prioritas yang digunakan sebagai zona produksi tanaman kayu putih.

\section{METODE}

\section{Lokasi Penelitian}

Penelitian dilaksanakan di RPH Gubugrubuh, Kabupaten Gunungkidul. Kawasan ini secara geografis terletak antara $7.92-7.95{ }^{\circ} \mathrm{LS}$ dan $110.48-110.55{ }^{0} \mathrm{BT}$. Luas RPH Gubugrubuh mencapai 645 ha yang mencakup 5 wilayah pedesaan yaitu Banaran, Getas, Ngleri, Ngunut, dan Bleberan. Bentang lahan di wilayah penelitian didominasi oleh perbukitan karst yang termasuk zona Ledok-Wonosari. Elevasi kawasan bervariasi antara $100-200 \mathrm{~m}$ dpl dengan tingkat kelerengan mencapai $8-25 \%$. Kondisi iklim di kawasan ini termasuk kategori C menurut Schimdt dan Fergusson dengan curah hujan berkisar $1700-2000 \mathrm{~mm} /$ tahun. Suhu lingkungan mencapai $22.3-32.4{ }^{\circ} \mathrm{C}$ dengan kelembaban nisbi sekitar $80-85 \%$. RPH Gubugrubuh memiliki 2 tipe tanah yaitu alfisol dan vertisol. Komoditi kehutanan yang dikembangkan di wilayah ini terdiri dari 2 jenis yaitu jati dan kayu putih (Haryanto, 2012). 


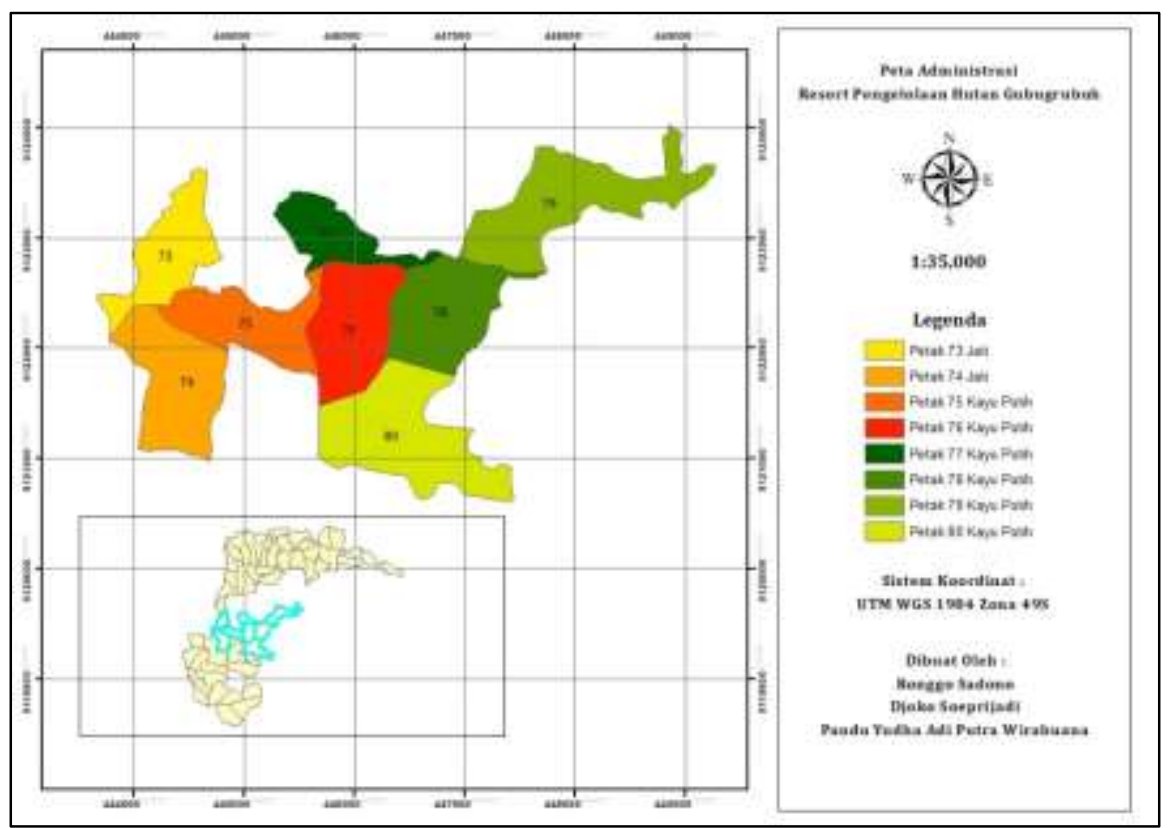

Gambar 1 Lokasi penelitian pada kawasan hutan tanaman RPH Gubugrubuh (Sumber: Sadono et al., 2019).

\section{Metode Pengumpulan Data}

Proses pengumpulan data dimulai dengan melakukan identifikasi petak yang menjadi area prioritas untuk penanaman kayu putih. Hasil pengamatan awal menunjukkan terdapat 3 petak yang menjadi prioritas lokasi pengembangan kayu putih yaitu petak 75,78 , dan 80 . Selanjutnya dilakukan pengukuran karakteristik lahan yang meliputi elevasi, kelerengan, suhu, curah hujan, kemasaman tanah, dan kandungan bahan organik tanah. Elevasi diukur dengan altimeter, sedangkan kelerengan diestimasi dengan klinometer. Pengukuran dilakukan secara random dengan 3 replikasi pada setiap petak.

Data tentang curah hujan dan suhu diperoleh dari stasiun pengamatan cuaca terdekat dari lokasi penelitian. Sedangkan analisis sifat tanah dilaksanakan melalui pengambilan sampel tanah secara terusik. Dalam konteks ini, sampel tanah dikumpulkan secara acak dari lapisan permukaan pada kedalaman $0-15 \mathrm{~cm}$ (Lin et al., 2014) dengan 3 replikasi pada setiap petak. Sampel tersebut selanjutnya dibawa ke laboratorium untuk diuji tingkat kemasaman dan kadar bahan organik. Penentuan nilai kemasaman tanah diukur dengan metode $\mathrm{pH}$ meter (Van Reeuwijk, 1993), sedangkan kadar bahan organik dianalisis dengan metode Walkey \& Black (Black, 1965).

Tabel 1 Prasyarat lahan untuk pertumbuhan tanaman kayu putih.

\begin{tabular}{lcclr}
\hline Kriteria & Simbol & Satuan & Sub Kriteria & Nilai \\
\hline Elevasi $^{*}$ & $\mathrm{~A}$ & $\mathrm{~m} \mathrm{dpl}$ & $30-100$ & 100 \\
& & & $101-200$ & 80 \\
& & & $201-300$ & 60 \\
& & & $301-400$ & 40 \\
& & & $>400$ & 20 \\
\hline Kelerengan $^{* *}$ & $\mathrm{~S}$ & $\%$ & $0-8$ & 100 \\
& & & $9-15$ & 80 \\
& & & $16-30$ & 60 \\
& & & $30-50$ & 40 \\
Suhu $^{*}$ & & & $>50$ & 20 \\
\hline
\end{tabular}




\begin{tabular}{|c|c|c|c|c|}
\hline Kriteria & Simbol & Satuan & Sub Kriteria & Nilai \\
\hline & & & $32-35 ; 20-22$ & 60 \\
\hline & & & $36-38 ; 17-19$ & 40 \\
\hline & & & $>38 ;<17$ & 20 \\
\hline \multirow[t]{5}{*}{ Curah hujan** } & $\mathrm{R}$ & $\mathrm{mm} /$ tahun & $1.201-1.500$ & 100 \\
\hline & & & $1.501-1.800 ; 801-1.200$ & 80 \\
\hline & & & $1.801-2.000 ; 601-800$ & 60 \\
\hline & & & $2.001-2.250 ;<600$ & 40 \\
\hline & & & $>2.250$ & 20 \\
\hline \multirow[t]{5}{*}{ Kemasaman tanah* } & $\mathrm{pH}$ & - & $6.01-6.50$ & 100 \\
\hline & & & $6.51-7.00 ; 5.51-6.00$ & 80 \\
\hline & & & 7.01-7.50;5.01-5.50 & 60 \\
\hline & & & 7.51-8.00;4.51-5.00 & 40 \\
\hline & & & $>8.00 ;<4.51$ & 20 \\
\hline \multirow[t]{5}{*}{ C organik ${ }^{* *}$} & SOC & $\%$ & $3,01-4,00$ & 100 \\
\hline & & & $4,01-8,00 ; 2,01-3,00$ & 80 \\
\hline & & & $8,01-12,00 ; 1,01-2,00$ & 60 \\
\hline & & & $12,01-15,00 ; 0,51-1,00$ & 40 \\
\hline & & & $>15,00 ;<0,51$ & 20 \\
\hline
\end{tabular}

Sumber : *Dibia (2015); ** Sudaryono (2010)

\section{Metode Analisis Data}

Data yang diperoleh selanjutnya direkapitulasi untuk disajikan secara deskriptif dalam bentuk tabulasi. Evaluasi kesesuaian lahan dilakukan melalui pola matching systems yaitu membandingkan antara karakteristik lahan dengan prasyarat tumbuh tanaman kayu putih (Tabel 1). Selanjutnya dilakukan perhitungan nilai indeks lahan dengan metode storie dan root square melalui persamaan matematis (Sys et al., 1991) :

a. Metode Storie

b. Metode Root Square

$$
I=A x \frac{B}{100} x \frac{C}{100} x \ldots
$$

$$
I=R_{\min } \sqrt{\frac{A}{100} \times \frac{B}{100} x \ldots}
$$

dimana $I$ merupakan indeks lahan. $A, B, C, \ldots$ merepresentasikan skor kesesuaian lahan dengan prasyarat tumbuh kayu putih. Rmin adalah skor minimum kesesuaian atribut lahan terhadap prasyarat tumbuh kayu putih. Berdasarkan nilai indeks lahan yang diperoleh selanjutnya ditentukan klasifikasi kesesuaian lahan (Tabel 2). Penentuan alternatif strategi silvikultur dirumuskan berdasarkan sifat lahan yang menjadi faktor pembatas bagi pertumbuhan kayu putih, ditandai dengan skor kesesuain terendah. 
Tabel 2 Klasifikasi kelas kesesuaian lahan berdasarkan nilai indeks lahan.

\begin{tabular}{llc}
\hline Indeks lahan & \multicolumn{1}{c}{ Kelas kesesuaian } & Simbol \\
\hline $75-100$ & Sangat sesuai & $\mathrm{S}_{1}$ \\
$50-75$ & Sesuai & $\mathrm{S}_{2}$ \\
$25-50$ & Sesuai marginal & $\mathrm{S}_{3}$ \\
$12.5-25$ & Tidak sesuai saat ini & $\mathrm{N}_{1}$ \\
$0-12.5$ & Tidak sesuai permanen & $\mathrm{N}_{2}$ \\
\hline
\end{tabular}

Sumber : Albaji et al. (2009)

\section{HASIL DAN PEMBAHASAN}

Tabel 3 memperlihatkan perbandingan karakteristik lahan pada setiap petak pengembangan kayu putih. Elevasi pada ketiga lokasi dikategorikan sebagai dataran rendah karena terletak pada rentang kurang dari 700 $\mathrm{m}$ dpl (Nakashizuka, 1991). Lokasi penanaman tertinggi berada pada petak 78 dengan kisaran $200-203 \mathrm{~m}$ dpl. Berpedoman pada klasifikasi kelerengan lahan (Pramanik, 2016), bentang lahan pada lokasi pengembangan kayu putih didominasi oleh daerah landai dengan tingkat kelerengan mencapai $8-15 \%$. Akan tetapi, terdapat petak penanaman yang memiliki kondisi lahan agak curam yaitu petak 75 dengan kisaran kelerengan mencapai $16-25 \%$.

Tabel 3 Karakteristik lahan pada petak prioritas pengembangan kayu putih di RPH Gubugrubuh.

\begin{tabular}{lccc}
\hline Parameter lahan & Petak 75 & Petak 78 & Petak 80 \\
\hline Elevasi $(\mathrm{m} \mathrm{dpl})$ & $163-171$ & $200-203$ & $172-185$ \\
Kelerengan $(\%)$ & $16-25$ & $8-15$ & $8-15$ \\
Suhu $\left({ }^{\circ} \mathrm{C}\right)$ & $23.2-32.4$ & $23.2-32.4$ & $23.2-32.4$ \\
Curah hujan (mm/tahun) & $1850-2000$ & $1850-2000$ & $1500-1750$ \\
Kemasaman tanah & $6.10-6.50$ & $5.50-6.00$ & $5.50-6.00$ \\
C organik $(\%)$ & $2.48-3.23$ & $2.56-3.11$ & $1.57-2.2$ \\
\hline
\end{tabular}

Tabel 3 menunjukkan bahwa variasi suhu dari setiap petak memiliki rentang yang sama yaitu $23.2-32.4$ ${ }^{0} \mathrm{C}$, namun terdapat perbedaan curah hujan pada petak penanaman. Secara umum curah hujan di ketiga lokasi termasuk kategori rendah dengan kisaran 1500 - $2000 \mathrm{~mm} /$ tahun (Sarfaraz, 2014). Curah hujan terendah ditemukan pada petak 80 yang mencapai $1500-1750 \mathrm{~mm} / \mathrm{tahun}$. Selain variabel curah hujan, komponen sifat tanah baik kemasaman tanah maupun kandungan bahan organik juga memperlihatkan perbedaan pada setiap petak. Kemasaman tanah terendah terdapat pada petak 75 yang mencapai $6.10-6.50$. Sedangkan kandungan bahan organik terendah ditemukan pada petak 80 yang berkisar $1.57-2.20 \%$. Berdasarkan klasifikasi tingkat kemasaman tanah dan kandungan bahan organik (Nandini dan Narendra, 2012), ketiga petak memiliki tingkat kemasaman tanah yang termasuk kategori agak masam dengan kadar bahan organik dari rendah sampai tinggi.

Hasil penilaian kesesuaian lahan dengan metode storie menunjukkan bahwa kelas kesesuaian lahan pada ketiga petak termasuk kategori N1 (tidak sesuai untuk saat ini). Ouput ini berbeda dengan metode root square yang memperlihatkan bahwa kesesuaian lahan dari ketiga lokasi termasuk kategori S3 (sesuai marginal). Atribut lahan yang menjadi faktor pembatas pertumbuhan kayu putih berbeda untuk setiap petak. Kelerengan lahan dan curah hujan menjadi faktor pembatas pengembangan kayu putih pada petak 75 , sedangkan kandungan bahan organik menjadi aspek penghambat pertumbuhan kayu putih pada petak 80. Sifat lahan yang menjadi pembatas pertumbuhan kayu putih di petak 78 adalah elevasi dan curah hujan (Tabel 4). 
Tabel 4 Kelas kesesuaian lahan pada petak pengembangan kayu putih.

\begin{tabular}{cccccc}
\hline \multirow{2}{*}{ Petak } & \multicolumn{4}{c}{ Indeks kesesuaian lahan } & \multirow{2}{*}{$\begin{array}{c}\text { Faktor } \\
\text { Pembatas }\end{array}$} \\
\cline { 2 - 5 } & Storie & $\begin{array}{c}\text { Kelas } \\
\text { Kesesuaian }\end{array}$ & Root Square & $\begin{array}{c}\text { Kelas } \\
\text { Kesesuaian }\end{array}$ & SR \\
\hline 75 & 23.04 & $\mathrm{~N}_{1}$ & 28.80 & $\mathrm{~S}_{3}$ & AR \\
78 & 23.04 & $\mathrm{~N}_{1}$ & 38.40 & $\mathrm{~S}_{3}$ & SOC \\
\hline
\end{tabular}

Dibandingkan metode storie, ouput evaluasi kesesuaian lahan dengan metode root square menyajikan informasi yang lebih relevan dalam konteks pengembangan tanaman secara komersial. Argumen ini dirumuskan berdasarkan fakta bahwa tanaman kayu putih di RPH Gubugrubuh mampu menghasilkan produksi daun yang cukup menjanjikan meskipun terdapat variasi hasil panen dari setiap petak. Pernyataaan ini juga didukung dengan hasil penelitian lain yang menyebutkan bahwa prosedur evaluasi kesesuaian lahan berbasis metode root square menghasilkan luaran informasi yang lebih realistis untuk digunakan sebagai acuan dalam budidaya sektor pertanian, perkebunan, dan kehutanan (Jafarzadeh et al., 2008; Albaji et al., 2009; Dengiz et al., 2010)

Berpedoman pada hasil penilaian kesesuaian lahan, terdapat 4 sifat lahan yang berperan sebagai faktor pembatas untuk mendukung budidaya kayu putih di RPH Gubugrubuh yaitu elevasi, kelerengan lahan, curah hujan, dan kadar bahan organik. Elevasi merupakan atribut lahan yang berpengaruh terhadap perubahan suhu (Chua et al., 2015). Variabel ini termasuk aspek topografi yang tidak dapat dimanipulasi melalui intervensi silvikultur (Dahlgren dan Ehrlen, 2009). Namun, studi ini tidak menemukan adanya perbedaan variasi suhu antar petak meskipun terdapat perbedaan rentang elevasi.

Kelerengan lahan dan curah hujan merupakan sifat lahan yang berhubungan dengan potensi erosi. Semakin tinggi level kelerengan dan intensitas curah hujan, maka potensi erosi semakin besar (Mu et al., 2015). Erosi dapat menyebabkan penurunan kesuburan tanah karena menyebabkan proses pelindihan hara (Murthy et al. 2016). Dalam rangka mengurangi resiko erosi, pembuatan terasering dan pengaturan kerapatan pola tanam dapat menjadi alternatif teknik silvikultur. Strategi ini secara konsisten berpotensi untuk menghambat laju aliran permukaan yang menjadi faktor penyebab erosi.

Konsentrasi bahan organik tanah memiliki keterkaitan dengan ketersediaan nutrisi yang dapat diserap oleh tanaman kayu putih. Kadar bahan organik yang rendah dapat ditingkatkan melalui kegiatan pemupukan. Hasil penelitian telah banyak membuktikan bahwa pemupukan secara signifikan dapat meningkatkan kandungan bahan organik tanah. Akan tetapi, pemberian pupuk harus dilakukan secara terkontrol agar tidak meningkatkan kemasaman tanah (Makinde et al., 2009; Liu et al., 2014; Rakkar et al., 2015). Studi lain juga membuktikan bahwa penambahan bahan organik tanah secara signifikan dapat meningkatkan kapasitas infiltrasi tanah sehingga berpotensi mengurangi erosi (Silva et al., 2011; Arevalo-Gardini et al., 2015; Brar et al., 2015).

\section{SIMPULAN}

Evaluasi kesesuaian lahan dengan metode root square memperlihatkan hasil yang lebih relevan daripada metode storie. Kelas kesesuaian lahan pada petak pengembangan kayu putih di RPH Gubugrubuh secara keseluruhan termasuk kategori S3 (sesuai marginal). Atribut lahan yang menjadi faktor pembatas pertumbuhan kayu putih bervariasi untuk setiap petak mencakup elevasi, kelerengan, curah hujan, dan kandungan bahan organik. Teknik silvikultur yang dapat diterapkan untuk meningkatan daya dukung lahan terhadap tanaman kayu putih meliputi pembuatan teras, pengaturan pola tanam, dan pemupukan. Berdasarkan hasil penelitian ini kami menyarankan untuk melakukan proses identifikasi kesesuaian lahan bagi pengembangan tanaman kayu putih di lokasi lain yang dimaksudkan untuk kepentingan komersial sehingga produktivitas kayu putih dapat ditingkatkan dengan preskripsi silvikultur yang tepat. 


\section{UCAPAN TERIMA KASIH}

Kami menyampaikan rasa terima kasih kepada para pihak yang telah membantu dalam pelaksanaan penelitian ini di antaranya adalah Dr. Priyono Suryanto yang telah memfasilitasi untuk menjalin kerjasama penelitian dengan KPH Yogyakarta serta pengelola RPH Gubugrubuh yang telah mengizinkan implementasi kegiatan penelitian di wilayahnya. Ucapan terima kasih juga ditujukan kepada reviewer yang telah memberikan saran dan masukan dalam memperbaiki naskah artikel ini.

\section{DAFTAR PUSTAKA}

Albaji M, Naseri A, Papan P, Nasab S. 2009. Qualitative evaluation of land suitability for principal crops in the west shoush plain, southwest Iran. Bulgarian Journal of Agricultural Science. 2(15):135-145.

Arevalo-Gardini E, Canto M, Alegre J, Loli O, Julca A, Baligar V. 2015. Changes in soil physical and chemical properties in long term improved natural and traditional agroforestry management systems of cacao genotypes in Peruvian Amazon. PLOS ONE. 10(7):1-29.

Bhagat VS. 2012. Use of remote sensing techniques for robust digital change detection of land : A review. Recent Pattern Space Technology. 2:124-144.

Black CA. 1965. Chemical and mikrobiological properties. In : Methods of soil analysis. Wisconsin-Madinson: American Society.

Brar BS, Singh J, Singh G, Kaur G. 2015. Effect of long term application of inorganic and organic fertilizer on soil organic carbon and physical properties in maize-wheat rotation. Agronomy. 5:220-238.

Budiadi, Ishii HT, Sabarnurdin MS, Suryanto P, Kanazawa Y. 2006. Biomass cycling and soil properties in an agroforestry-based plantation system of kayu putih (Melaleuca leucadendron LINN) in East Java, Indonesia. Agroforestry Systems. 67:135-145.

Budiadi, Ishii HT. 2010. Comparison of carbon sequestration between multiple-crop, single-crop and monoculture agroforestry systems of melaleuca in Java, Indonesia. Journal of Tropical Forest Science. 22(4):378-388.

Budiadi, Kanazawa Y, Ishii HT, Sabarnurdin MS, Suryanto P. 2005. Productivity of kayu putih (Melaleuca leucadendron LINN) tree plantation managed in non-timber forest production systems in Java, Indonesia. Agroforestry Systems. 64:143-155.

Chua IY, King PJ, Ong KH, Sarbini SR, Yiu PH. 2015. Influence of light intensity and temperature on antioxidant activity in Premna serratifolia L. Journal of Soil Science and Plant Nutrition. 15(3):605614.

Dahlgren JP, Ehrlen J. 2009. Linking environmental variation to population dynamics of a forest herbs. Journal of Ecology. 97:666-674.

Dengiz O, Gol C, Sarioglu FE, Edis S. 2010. Parametric approach to land evaluation for forest plantation. African Journal of Agriculture Research. 5(12):1482-1496.

Dibia IY. 2015. Land suitability evaluation for cajuput development (Melaleuca leucadendra) in western plantation Bali (Grograk Sub-District), Buleleng District. Agrotrop. 5 (2):194-205.

Girma R, Moges A, Quraishi S. 2015. GIS based physical land suitability evaluation for crop production in eastern Ethiopia : a case study in Jello Watershed. Agrotechnology. 5(1):2-7.

Haryanto, S. 2012. Planning of cajuput plantation management. Yogyakarta Forest Management Unit Official, Yogyakarta.

Helfiansah R, Sastrohamidjojo H, Riyanto. 2013. Isolation, identification and purification cinneol materials 1.8 of cajuput oil (Melaleuca leucadendron). ASEAN Journal of Systems Engineering. 1(1):19-24.

Jafarzadeh AA, Alamdari P, Neyshabouri MR, Saedi S. 2008. Land suitability evaluation of Bilverdy Research Station for wheat, barley, alfalfa, maize, and safflower. Soil and Water Resource. 3(1):81-88. 
Junaidi E, Winara A, Siarudin M, Indrajaya Y, Widiyanto A. 2015. Spatial distribution of plant cajuput oil in Wasur National Park. Journal of Wallacea Forestry Research. 4(2):101-113.

Liu CW, Sung Y, Chen BC, Lai HY. 2014. Effects of nitrogen fertilizers on the growth and nitrate content of lettuce (Lactuca sativa L.). International Journal of Environmental Research and Public Health. 11:4427-4440.

Makinde EA, Eniola HT, Fagbola O. 2009. Effect of organic, organomineral, and NPK fertilizers on soil pH, organic matter, and micronutrient content in two soil types. Research on Crops. 10:77-85.

Malekian A, Jafar zadeh AA. 2011. Qualitative land suitability evaluation of the Khajeh Research Station for wheat, barly, alfafa, maize, and safflower. Research in Plant Biology. 1(5):33-40.

Memarbashi E, Azadi H, Barati AA, Mohajeri F, Van Passel S, Witlox F. 2017. Land-use suitability in Northeast Iran : application of AHP-GIS hybrid model. International Journal of Geo-Information. 6(396):1-15.

Mohd SN, Majid NM, Shazili NM, Abdu A. 2013. Growth performance, biomass, and phytoextraction efficiency of Acacia mangium and Melaleuca cajuput in remediating heavy metal contaminated soil. American Journal of Environmental Science. 9(4):310-316.

Mu W, Yu F, Li C, Xie Y, Tian J, Liu J, Zhao N. 2015. Effects of rainfall intensity and slope gradient on runoff and soil moisture content on different growing stages of spring maize. Water. 7:2990-3008.

Murthy IK, Dutta S, Varghese V, Joshi PP, Kumar P. 2016. Impact of agroforestry systems on ecological and socio-economy system : a review. Global Journal of Science Frontier Research. 16(5):15-27.

Nakashizuka T. 1991. Altitudinal zonation of forest communities in Selangor, Peninsular Malaysia. Journal of Tropical Forest Science. 4(3):233-244.

Nandini R, Narendra BH. 2012. Critical land characteristics of former eruption of Batur Mount in Bangli District, Bali. Journal of Forest Research and Nature Conservation. 9(3):199-211.

Nethononda LO, Odhiambo JO, Paterson DG. 2014. Land suitability for specific crop ranges using dynamic land suitability evaluation guidelines for small-scale communal irrigation schemes. Bulgarian Journal of Agricultural Science. 20(6):1349-1360.

Page S, Hoscilo A, Wosten H, Jauhiainen J, Silvius M, Rieley J, Limin S. 2009. Restoration ecology of lowland tropical peatlands in Southeast Asia : current knowledge and future directions. Ecosystems. 12:888-905.

Pramanik MK. 2016. Site suitability analysis for agricultural land use of Darjeeling District using AHP and GIS techniques. Modeling Earth Systems and Environment. 2(56):1-22.

Rakkar MK, Franzen DW, Chatterjee A. 2015. Evaluation of soil potassium test to improve fertilizer recommendations for corn. Open Journal of Soil Science. 5:110-122.

Sadono R, Soeprijadi D., Wirabuana PYAP. 2019. Effect of soil chemical properties on the growth of cajuput stand (Melaleuca leucadendron (L.) Linnaeus). Journal of Wallacea Forestry Research. 8(1):1-7.

Sarfaraz S. 2014. The sub-regional classification of Pakistan's winter precipitation based on principal components analysis. Pakistan Journal of Meteorology. 10(20):57-66.

Sharififar A. 2012. Assessment of different methods of soil suitability classification for wheat cultivation. Journal of Agrobiology. 29(2):47-54.

Silva GL, Lima HV, Campanha MM, Gilkes RJ, Oliveira TS. 2011. Soil physical quality of luvisols under agroforestry, natural vegetation and conventional crop management systems in the Brazilian semi-arid region. Geoderma. 167-168:61-70.

Sudaryono. 2010. Land suitability evaluation for cajuput in Buru District, Maluku Province. Journal of Environmental Enginering. 11(1):105-116.

Suryanto P, Tohari, Putra E, Alam T. 2017. Minimum soil quality determinant for rice and 'kayu putih' yield under hilly areas. Journal of Agronomy. 16:115-123. 
Sys C, Vanranst E, Debaveye J. 1991. Method in land evaluation. In : Land evaluation. Ghent: Internasional training center for post graduate soil scientist and Ghent University.

Tata HL, Pradjadinata S. 2015. Native species for degraded peat swamp forest rehabilitation. Journal of Tropical Silviculture. 7:580-582.

Van Reeuwijk LP. 1993. Technology paper. In : Procedure for soil analysis. Wageningen: Internasional Soil Reference and Information Center, Wageningen.

Zhang J, Su Y, Wu J, Liang H. 2015. GIS based land suitability assessment for tobacco production using AHP and fuzzy set in Shandong province of China. Computation Electronical Agriculture. 114:202-211. 